\title{
Electrical swing adsorption on functionalized hollow fibers
}

\author{
Laura Keller ${ }^{\mathrm{a}, * *}$, Theresa Lohaus ${ }^{\mathrm{a}, * *}$, Lorenz Abduly ${ }^{\mathrm{a}}$, Greta Hadler ${ }^{\mathrm{a}}$, Matthias Wessling ${ }^{\mathrm{a}, \mathrm{b}, *}$ \\ ${ }^{a}$ RWTH Aachen University, Chemical Process Engineering, Forckenbeckstr. 51, 52074 Aachen, Germany \\ ${ }^{b}$ DWI - Leibniz Institute for Interactive Materials, Forckenbeckstr. 50, 52074 Aachen, Germany
}

\section{Abstract}

Temperature swing adsorption (TSA) is a favorable adsorption technique when applied for capturing $\mathrm{CO}_{2}$ but limited by long cycle times and low concentrations of the recovered adsorbate. Direct heating of the adsorbent can mitigate these drawbacks. Combined with the beneficial mass transfer of a hollow fiber geometry it offers a powerful sorption process. In this study, we combine the advantages of direct heating and the benefits of the hollow fiber geometry in electrically conducting hybrid hollow fibers. Two different solid sorbents are manufactured and characterized: polyethylenimine-impregnated silicon carbide fibers (SiC-PEI) and fibers consisting of a carbon nanotube matrix with dispersed zeolite particles (CNT-zeolite). Both fibers exhibit Joule heating properties and high adsorption capacities. The $\mathrm{CO}_{2}$ uptake, $\mathrm{CO}_{2}$ isotherms, and the kinetic behavior are examined. The maximum $\mathrm{CO}_{2}$ uptakes at $30^{\circ} \mathrm{C}$ and $15 \mathrm{vol} \% \mathrm{CO}_{2}$ are $8.3 \mathrm{mg} / \mathrm{g}_{\text {fiber }}$ for $\mathrm{SiC}-\mathrm{PEI}$ and $102.2 \mathrm{mg} / \mathrm{g}_{\text {fiber }}$ for CNT-zeolite. A lab-scale module is designed and used to determine the $\mathrm{CO}_{2}$ capacity of a fiber bundle. The energy requirement to heat such a fiber bundle from ambient temperature to $80^{\circ} \mathrm{C}$ is $3.1 \mathrm{~J} /\left(\mathrm{g}_{\text {Fiber }} \mathrm{K}\right)$ (SiC-PEI) and $15.8 \mathrm{~J} /\left(\mathrm{g}_{\text {Fiber }} \mathrm{K}\right)$ (CNT-zeolite). To investigate the suitability of the fibers for real process applicability, a mathematical model is established

\footnotetext{
*Corresponding author. Tel: +4924180 95470. E-mail: Manuscripts.CVT@avt.rwth-aachen.de

${ }^{* *}$ Contributed equally to this work
} 
and simulation results are presented and discussed. The two different approaches prove to be viable options for $\mathrm{CO}_{2}$ separation. They are not limited to $\mathrm{CO}_{2}$ capture but can be expanded to other gas separation tasks.

Keywords: Electrical swing adsorption, heatable hollow fiber, PEI, zeolite, $\mathrm{CO}_{2}$ capture

\section{Introduction}

Temperature swing adsorption (TSA) is a well-established technology for the separation and purification of different gas streams [1]. In particular, when large streams or dilute systems are separated, TSA processes offer benefits over pressure swing adsorption (PSA) processes, for instance when purifying natural gas [2] or for direct air capture of $\mathrm{CO}_{2}$ [3]. Temperature swing adsorption processes are also favorable for capturing $\mathrm{CO}_{2}$ from flue gases to reduce anthropogenic greenhouse gas emissions $[4,5] . \quad \mathrm{CO}_{2}$ removal is an imperative measure if global warming is to be limited to $1.5^{\circ} \mathrm{C}[6]$. In common TSA applications, a stream of hot steam or gas passes the adsorption column to heat the adsorbent [7] and thus reduce its adsorption capacity for regeneration. The main limitations of TSA are long cycle times usually in the range of several hours [8], thermal aging of the adsorbent [9], and low concentrations of the recovered adsorbate depending on the volume of the required gas stream for heating [1].

Direct heating methods of the adsorbent can efficiently overcome these main limitations making TSA a process that can potentially outperform other separation techniques. Among the methods for alternative heating of the adsorbent are electrical heating (Joule heating) [10], induction heating [11], and microwave heating [12,13]. Electrical regeneration uses the Joule effect of an electrically conductive adsorbent under applied electric voltage, which means the 
conversion of the electric power at the electrical resistance to thermal heat that dissipates from the adsorbent. Sullivan et al. [14] state that electrical heating is the most promising regeneration method among the new heating concepts due to even heating of the adsorbent and low energy losses from the power source to the adsorbent.

The main advantage of electric swing adsorption (ESA) is the higher heating efficiency resulting from the direct local heat input at the adsorbent. Local heating enables much faster cycle times, as the heating rate does not depend on the heat capacity of the heat source and thus the rate of heat transfer between the adsorbent, and the heat source disappears as a limiting factor $[14,15]$. Additionally, the control of gas flow is independent of the heat flow. This independent control allows designing smaller systems with a lower purge gas flow [16] avoiding dilution of the product. The adsorbate can, therefore, be captured with higher purities. ESA further promises to be superior to other forms of TSA from the energy point of view $[8,10]$.

To capture $\mathrm{CO}_{2}$ using an ESA approach appropriate sorbents have to be identified. According to Grande et al. [2], suitable materials are zeolites and amine impregnated solid sorbents. Other sorbents for $\mathrm{CO}_{2}$ capture with ESA include activated carbon fibers [15, 17, 18], carbon monoliths [3, 19, 20], monoliths composed of carbon and zeolites [21, 22], and graphene-based sorbents [23]. Polymeric amines are considered favorable for $\mathrm{CO}_{2}$ separation processes [24] as they absorb $\mathrm{CO}_{2}$ remarkably well compared to other gases. Amine impregnated solid sorbents offer high chemical stability and can be applied under humid conditions [25] while some studies even report increasing adsorption capacities in the presence of water [26-28]. Zeolites also have a number of advantages when used for $\mathrm{CO}_{2}$ capture. They exhibit high $\mathrm{CO}_{2}$ uptake at low partial pressures as well as high selectivities of $\mathrm{CO}_{2}$ 


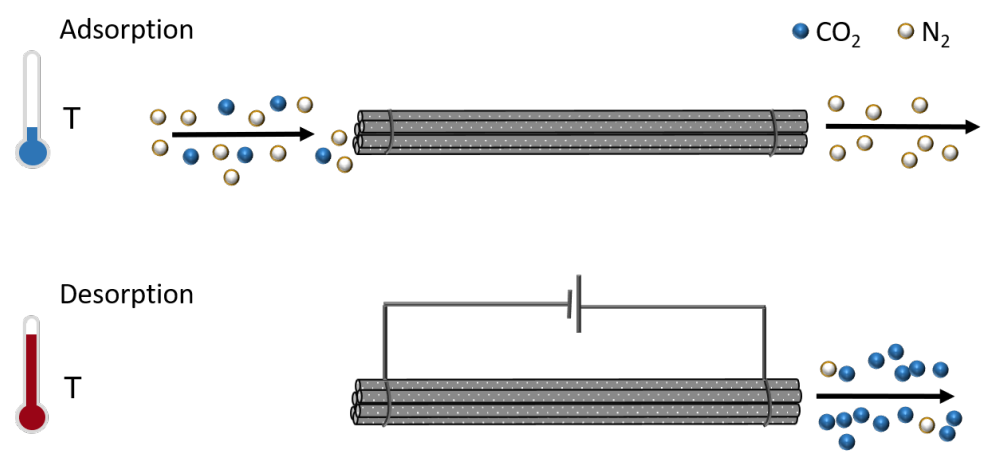

Figure 1: Schematic representation of the adsorption and electrically induced desorption step in a hollow fiber bundle.

over $\mathrm{N}_{2}[29,30]$, their adsorption kinetics are very fast, filling most of the total capacity within seconds, while their regenerability is seldom prone to degeneration yielding stable $\mathrm{CO}_{2}$ uptake capacities over many cycles [31].

Generally, adsorption columns use packed beds with inherent limitations such as a high mass transfer resistance [32], a high heat transfer resistance as well as undefined flow conditions. Fibrous sorbents promise to overcome fundamental shortcomings of TSA processes [3335]. Feng et al. [33] were the first to introduce a hollow fiber geometry which resulted in a lower pressure drop and a lower mass transfer resistance. Controlled flow conditions in the laminar regime led to sharper breakthrough curves and thus higher recoveries [33].

In this study, we perform ESA on a hollow fiber geometry, schematically illustrated in Figure 1. Highly adsorptive, electrically conductive fibers serve as electrical resistances for direct heating of the adsorbent regeneration combined with the improved mass transfer of the hollow fiber geometry. We compare two different adsorbent-fiber composites: silicon carbide (SiC) fibers impregnated with polyethyleneimine (PEI) and zeolites incorporated into a carbon nanotube (CNT) matrix. Previous work proved the applicability of PEI-impregnation on 
hollow fibers and the suitability of CNT-based solid sorbents for $\mathrm{CO}_{2}$ capture [36, 37]. Both $\mathrm{CNT}$ and $\mathrm{SiC}$ feature excellent thermal and chemical stability, and low thermal expansion coefficients. They provide a stable framework, are electrically conductive, and have a high surface-to-volume ratio. PEI and zeolites increase the $\mathrm{CO}_{2}$ adsorption capacity of the fibers. Adsorption isotherms and kinetics of the fibers are presented and their electrical heatability is shown. Arranged in fiber bundles, the fibers are used in a prototype module to prove the promising performance of hollow fibers as ESA bundles.

\section{Experimental}

\subsection{Materials}

The following chemicals were used without further purification: Polyethyleneimine (branched, molecular weight: 800 Da, Sigma Aldrich), Triton X-100 (Sigma Aldrich), carbon nanotubes (multi-walled, $\geq 98 \%$ carbon basis, outer diameter: $10 \mathrm{~nm} \pm 1 \mathrm{~nm}$, inner diameter: $4.5 \mathrm{~nm}$ $\pm 0.5 \mathrm{~nm}$, length: $3-6 \mu \mathrm{m}$, Sigma-Aldrich), zeolite ( $\mathrm{NaY}$ zeolite, $\mathrm{SiO}_{2} / \mathrm{Al}_{2} \mathrm{O}_{3}$-mole ratio: 5.1, Zeolyst CBV100), polyurethane glue PU1000 (Polytec), silver conductive paste (Sigma Aldrich), ethanol (purity: > 98.8 vol \%, Overlack), isopropyl alcohol (98\% purity, Applichem), $\mathrm{CO}_{2}$ (purity: 4.5, Westfalen $\mathrm{AG}$ ), gas mixture 15 vol $\% \mathrm{CO}_{2}, 85$ vol $\% \mathrm{~N}_{2}$ (purity: $\mathrm{CO}_{2}: 3.0$, $\mathrm{N}_{2}: 4.8$, Westfalen $\left.\mathrm{AG}\right)$.

\subsection{Fiber preparation and characterization}

$\mathrm{SiC}$ fibers were synthesized according to de Wit et al. [38] by sintering at $1000^{\circ} \mathrm{C}$. A short description can be found in the Supporting Information. Two methods were applied for impregnating SiC fibers with PEI. A solution of $5 \mathrm{wt} \%$ PEI in ethanol was used in both 
approaches. Following a common wet impregnation method [39], the fiber was suspended in a stirred PEI solution for $6 \mathrm{~h}$ with subsequent drying overnight under vacuum $\left(30^{\circ} \mathrm{C}, 90 \mathrm{mbar}\right)$. For the second impregnation method, the lower end of the fiber was sealed with glue while PEI solution was filtered inside-out through the fiber into the stirred PEI bath with a flux of $100 \mathrm{~L} \mathrm{~m}^{-2} \mathrm{~h}^{-1}$. A total volume of $40 \mathrm{~mL}$ was filtered through one fiber. The subsequent drying was carried out according to the stirring approach. The sealed end of the fiber was removed. The total amount of immobilized PEI $m_{P E I}$ was calculated by the weight difference before and after the immobilization: $m_{P E I}=m_{\text {coated }}-m_{\text {uncoated }}$ and the specific load of the fiber $m_{P E I} \prime \prime$ amounts to $m_{P E I} \prime \prime=\frac{m_{\text {coated }}-m_{\text {uncoated }}}{m_{\text {coated }}}$, where $m_{\text {uncoated }}$ is the mass of the pure SiC fiber and $m_{\text {coated }}$ the mass of the fiber impregnated with PEI.

A detailed description of the synthesis of the CNT fibers can be found in Gendel et al. [40]. To incorporate the zeolite particles, $4 \mathrm{gL}^{-1}$ zeolite were added to the aqueous suspension (deionized water, $18 \Omega \mathrm{cm}$ ) with $1 \mathrm{vol} \%$ surfactant (Triton X-100), $1 \mathrm{~g} \mathrm{~L}^{-1} \mathrm{CNT}$ powder used for the fiber preparation. Thus, a ratio of CNT to zeolite of $20 / 80 \mathrm{wt} \%$ was achieved. The synthesis is described in short in the Supporting Information.

Electron micrographs were taken with a scanning electron microscope S4800 of Hitachi. The samples were dried under vacuum overnight $\left(30^{\circ} \mathrm{C}\right.$ and 90 mbar $)$ and sputtered with $6 \mathrm{~nm}$ gold/palladium (60:40, w:w) before analysis.

\subsection{Specific $\mathrm{CO}_{2}$ uptake and sorption kinetics}

Adsorption capacities and kinetics of the fibers were determined by thermogravimetric analysis (TGA) with a PerkinElmer Thermal Analyzer 6000. The fibers were measured with a constant gas flux of $150 \mathrm{~mL} \min ^{-1}$ of $\mathrm{N}_{2}, \mathrm{CO}_{2}$ or a gas mixture $\left(15 \mathrm{vol} \% \mathrm{CO}_{2}\right.$ in $\left.\mathrm{N}_{2}\right)$, re- 
spectively. The temperature program of SiC-PEI fibers consisted of desorbing any impurities and adsorbed $\mathrm{CO}_{2}$ at $110^{\circ} \mathrm{C}$ under $\mathrm{N}_{2}$ for 90 min. The desorption temperature was chosen such that as many impurities as possible would be removed while there was still a reasonable distance to the temperature at which PEI volatilizes and/or decomposes $\left(135^{\circ} \mathrm{C}\right)$ [41]. Temperature was then decreased to $30^{\circ} \mathrm{C}$ under $\mathrm{CO}_{2}$ or the gas mixture for $60 \mathrm{~min}$. The sample was again desorbed at $110^{\circ} \mathrm{C}$ under $\mathrm{N}_{2}$ for 90 min, before a second adsorption step at $80^{\circ} \mathrm{C}$ for 60 min under $\mathrm{CO}_{2}$ or the gas mixture was conducted. Staying under $\mathrm{CO}_{2}$, the temperature was increased to $110^{\circ} \mathrm{C}$ and then held for $60 \mathrm{~min}$. The temperature program for CNT-zeolite fibers started with a heating step under $\mathrm{N}_{2}\left(300^{\circ} \mathrm{C}\right.$ for $\left.120 \mathrm{~min}\right)$. Temperature was decreased every 45 min to $120^{\circ} \mathrm{C}, 100^{\circ} \mathrm{C}, 80^{\circ} \mathrm{C}, 60^{\circ} \mathrm{C}, 40^{\circ} \mathrm{C}$, and $30^{\circ} \mathrm{C}$ under $\mathrm{CO}_{2}$ or the gas mixture. To determine the sorption kinetics of the CNT-zeolite fibers additional measurements were necessary with the gas mixture of $15 \mathrm{vol} \%$. Three separate measurements with different fibers were conducted. First, a degassing step under $\mathrm{N}_{2}$ was performed at $250^{\circ} \mathrm{C}$ for $120 \mathrm{~min}$. Subsequently, an adsorption steps followed at $30^{\circ} \mathrm{C}, 50^{\circ} \mathrm{C}$, or $80^{\circ} \mathrm{C}$.

Adsorption capacities $c_{\mathrm{CO}_{2}}$ were calculated by

$$
c_{C O_{2}}=\frac{m_{i}-m_{0}}{m_{0}}
$$

where $m_{0}$ is the reference mass of the sample after desorption under $\mathrm{N}_{2}$, while $m_{i}$ is the mass after adsorption with $\mathrm{CO}_{2}$ at the respective temperature $i$.

\subsection{Sorption isotherms}

Pure $\mathrm{CO}_{2}$ sorption isotherms were measured at ambient temperature using pycnometry (ASAP 2020, Micromeritics) for pressures ranging from 0.004 to 1.1 bar. Degassing for pycnometry measurements was conducted under vacuum $(1.3 \mu \mathrm{bar})$ at $110^{\circ} \mathrm{C}$ for $6 \mathrm{~h}$ for the 
PEI-impregnated SiC fibers. CNT-zeolite fibers were degassed under vacuum (1.3 $\mu \mathrm{bar})$ at $250^{\circ} \mathrm{C}$ for $6 \mathrm{~h}$. The equilibrium criterion was $\frac{p_{n}-p_{n+1}}{p_{n}} \frac{1}{\Delta t}<4.5 \cdot 10^{-7} \frac{1}{s}$ which led to a variable equilibrium time for each pressure and each sample.

\subsection{Procedure for experiments with fiber bundles inside a module}

A bundle of 15 fibers with a length of $10 \mathrm{~cm}$ for each fiber type was tested in the module. The fibers were glued to bundles at their endings with electrically conductive glue. SiC-PEI was glued with Polytec PU1000 while CNT-zeolite was glued with silver conductive paste due to different wetting properties of the fiber materials. Copper wire was twined around both ends of the fibers for electrical connections.

To test the performance of the bundle in the module, we compared external heating tests to internal heating (Joule heating). For external heating, the sealed module with the bundle inside was flushed with pure $\mathrm{CO}_{2}$ for $30 \mathrm{~min}$. Inlet and outlet valves were then closed and a gas bag was connected to the outlet. The set-up was placed in an oven, heated to $80^{\circ} \mathrm{C}$ and held for 60 min with the outlet valve open to the gas bag which collected the desorbed $\mathrm{CO}_{2}$. Upon removal from the oven the valve of the bag was closed, the module was cooled to room temperature and the captured volume was measured by water displacement (see Figure S1). To correct for thermal expansion of the gas, the empty module was heated and the same procedure as described above was followed. The measured gas volume was then subtracted from the result of the external heating test.

The gas bag analysis was repeated with electrical heating meaning that instead of using an oven for heating, the fibers were heated with Joule heating by an applied voltage. The fibers were heated to $80^{\circ} \mathrm{C}$ and kept at this temperature for $15 \mathrm{~min}$. The desorbed volume 
was measured by water displacement analog to the oven heating procedure. This measured volume captured by the bag was corrected against the thermal expansion of the gas inside the module using the ideal gas law.

\subsection{Mathematical modelling}

A mathematical model was implemented to investigate breakthrough times, evaluate cycle times and estimate the energy requirement of an ESA process using the fibers presented in this work. High thermal conductivity and low mass transfer resistance of the hollow fiber sorbents [33-35] allow model simplifications to decrease mathematical complexity. Since all fibers are assumed to be equal and evenly distributed, the description of a single fiber is sufficient [42]. Further, the following assumptions were made:

- all gases are ideal gases,

- radial gradients for transfer of mass, heat, and momentum are neglected,

- only $\mathrm{CO}_{2}$ is adsorbed,

- the flow within the fiber is laminar and fully developed,

- the heat of adsorption is constant.

All relevant equations are stated in the Supporting Information.

\section{Boundary conditions and performance criteria}

A basic electric swing adsorption process comprises three steps namely an adsorption, a desorption and a regeneration step per cycle (see Figure 2). First, the open column is fed with gas containing $15 \mathrm{vol} \% \mathrm{CO}_{2}$ in $\mathrm{N}_{2}$ which corresponds to concentrations found in flue 


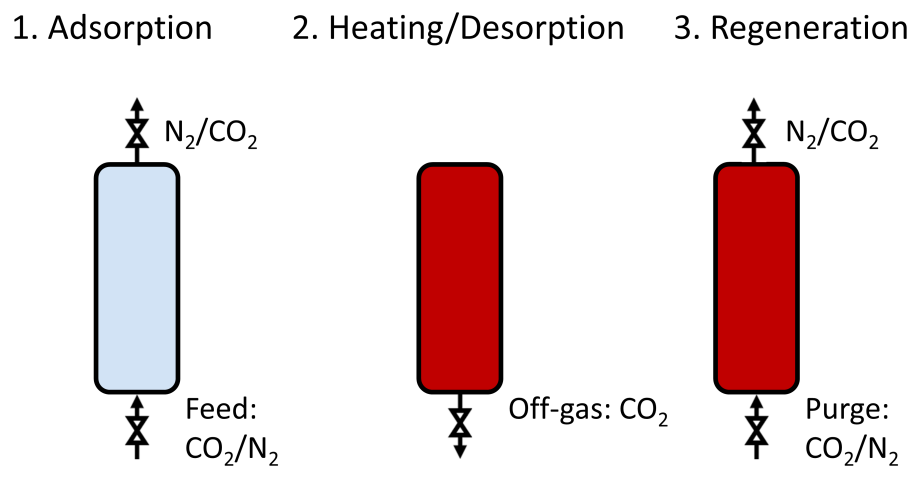

Figure 2: Three-step electric swing adsorption process including an adsorption step at ambient conditions, a desorption step including electric heating as well as partial vacuum, and a regeneration step for the column to reach ambient conditions, which includes cooling and optional pressurization.

gases [43]. The column is loaded to its full capacity to evaluate the maximum performance of our novel adsorption materials in terms of minimum energy requirement, recovery, and purity. Once the column is fully loaded, its outlet is closed and the system is electrically heated until the desired desorption temperature is reached. Simultaneously, a partial vacuum is generated at the inlet to enhance the desorption performance. Once the adsorbent is regenerated, the column is cooled and pressurized to ambient conditions (regeneration step). Mathematical boundary conditions are shown in the Supporting Information (Table S1).

Adsorption processes are often characterized by their minimum energy requirements (MER) per mass of recovered $\mathrm{CO}_{2}$ to compare different operating points [44]. For an ESA process, the MER is calculated by

$$
M E R=\frac{\Delta E_{t o t}}{\Delta M_{C O_{2}}}
$$

where $\Delta E_{\text {total }}$ is the total energy requirement per cycle and $\Delta M_{\mathrm{CO}_{2}}$ the amount of $\mathrm{CO}_{2}$ produced in this cycle. The corresponding equations for $\Delta E_{t o t}$ can be found in the Supporting 
Information. Additional process parameters such as the $\mathrm{CO}_{2}$ product stream purity and overall recovery are calculated by

$$
\begin{gathered}
\text { purity }=\frac{\int_{t_{\text {des }}}^{t_{\text {reg }}} M_{\text {product }_{C O}}}{\int_{t_{\text {des }}}^{t_{\text {reg }}} M_{\text {product }}} \\
\text { recovery }=\frac{\int_{t_{\text {des }}}^{t_{\text {reg }}} M_{\text {product }_{C O_{2}}}}{\int_{t_{\text {ads }}}^{t_{r e g}} M_{\text {feed }_{C O}}+M_{\text {regCO }}}
\end{gathered}
$$

where $\mathrm{t}_{a d s}, \mathrm{t}_{\text {des }}$ and $\mathrm{t}_{r e g}$ are the starting times of the adsorption, desorption and regeneration steps, respectively. $\mathrm{M}_{\text {product }}$ is the molar product stream and $\mathrm{M}_{\text {product } \mathrm{CO}_{2}}$ the molar $\mathrm{CO}_{2}$

product stream. For the recovery, the amount of $\mathrm{CO}_{2}$ fed in the adsorption step $\mathrm{M}_{\text {feed }_{\mathrm{CO}_{2}}}$ and in the regeneration step $\mathrm{M}_{\mathrm{reg}_{\mathrm{CO}}}$ are calculated. To compare different operating points in terms of desorption temperatures and pressures a reference case was established according to the experimental procedures presented before. Detailed operating conditions can be found in Table S2.

\section{Results and Discussion}

\subsection{Fiber characterization}

Two features are relevant for fibers used in an electrical swing adsorption process: high adsorption capacities and good electrical properties for fast Joule heating during desorption. The SiC-PEI fiber consists of an electrically conductive silicon carbide ( $\mathrm{SiC})$ support that is impregnated with polyethylenimine (PEI), a polymeric amine known for high adsorption capacities of $\mathrm{CO}_{2}$ also under humid conditions [30]. The CNT-zeolite fibers contain a high load of zeolites for a high adsorption capacity while the supporting carbon matrix provides 
electric conductivity. Different properties of the fibers such as the conductivity are displayed in Table 1. Figure 3 shows electron micrographs of the outer surface of both composite fibers and their cross section. The geometrical dimensions of the fibers are comparable to each other (see Table 1) where SiC-PEI has an outer diameter of $1.8 \mathrm{~mm}$ and an inner diameter of $0.8 \mathrm{~mm}$ while CNT-zeolite provides an outer diameter of $1.5 \mathrm{~mm}$ and an inner diameter of $1.3 \mathrm{~mm}$. Figure 3a shows the zeolite particles in the CNT matrix. The particles are homogeneously distributed within the structure. Figure $3 \mathrm{~b}$ shows the structure of $\mathrm{SiC}$ as a cluster of inorganic particles. The coating of $\mathrm{SiC}$ with PEI is thin and optically not distinguishable by microscopy.

Table 1: Properties of the SiC and CNT-zeolite fibers.

\begin{tabular}{ccc} 
Parameter & $\mathrm{SiC}$ & CNT-zeolite \\
\hline Pore diameter $(\mathrm{nm})$ & 500 & 1.6 \\
Inner diameter $(\mathrm{mm})$ & 0.8 & 1.3 \\
Outer diameter $(\mathrm{mm})$ & 1.8 & 1.5 \\
Conductivity $\left(\mathrm{kS} \mathrm{m}^{-1}\right)$ & 0.8 & 3.3 \\
\hline
\end{tabular}

Two different impregnation methods were tested to immobilize PEI on the SiC fibers: a simple wet impregnation method and a combined impregnation and filtration method. The combined method leads to an increase in immobilized PEI of about $20 \%$ compared to the simple wet impregnation method (see Table 2).

An increased amount of immobilized PEI on the $\mathrm{SiC}$ support potentially leads to higher adsorption capacities while not only the amount of PEI but also a good distribution and the 

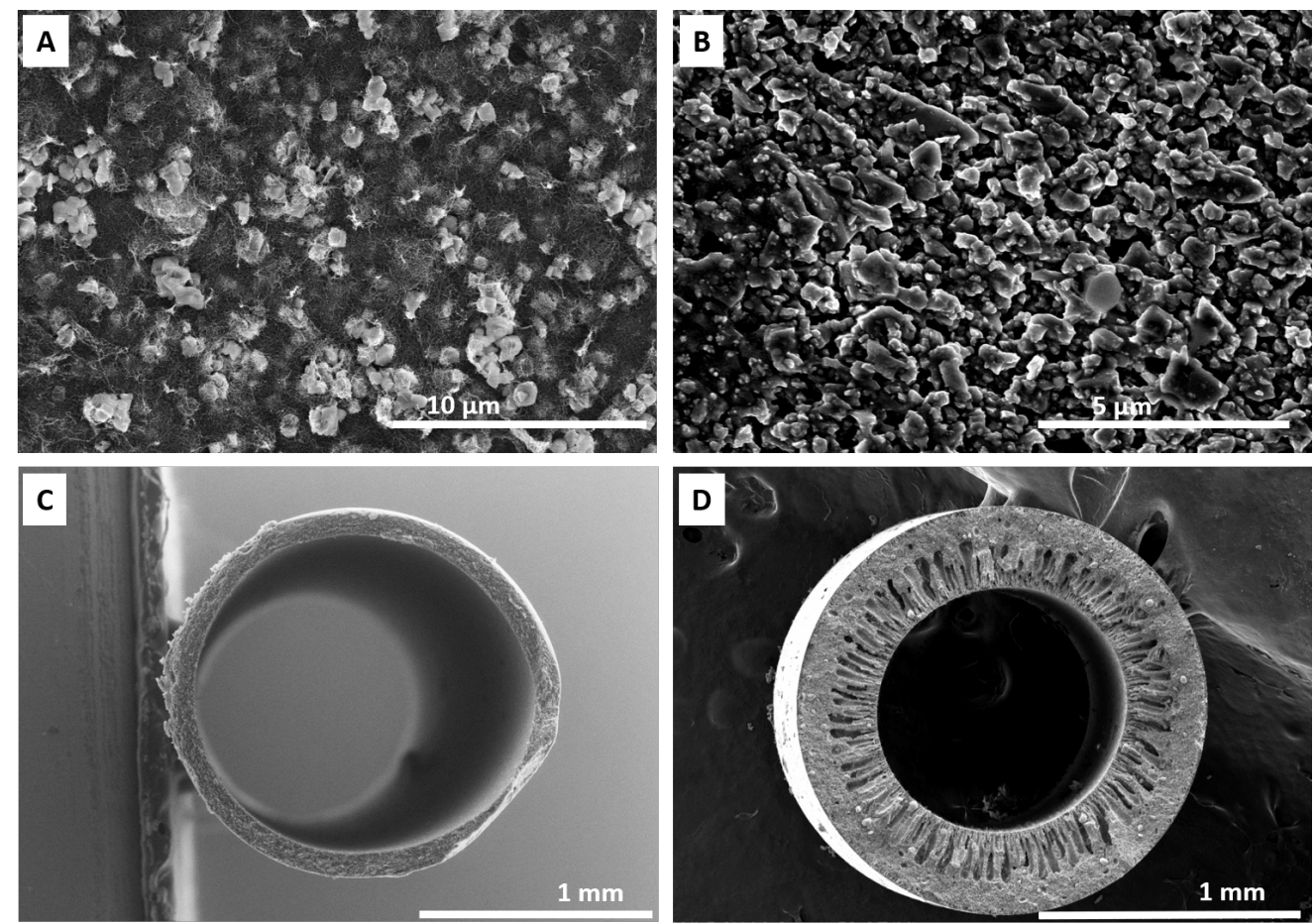

Figure 3: Electron microscopy images of the surface topology and the cross section of CNT-zeolite (A and C) and SiC-PEI (B and D) fibers. Images have been adapted in brightness.

Table 2: PEI load on SiC fibers prepared by different impregnation methods (numbers in brackets represent the standard error of the mean).

Filtered PEI Stirred PEI

\begin{tabular}{cc}
$\mathrm{mg}_{P E I} / \mathrm{g}_{S i C}$ & $\mathrm{mg}_{P E I} / \mathrm{g}_{S i C}$ \\
\hline $97.6(2.65)$ & $81.3(3.21)$
\end{tabular}

available internal surface area are relevant for high adsorption capacities [36]. When testing the adsorption capacities of both impregnation methods with TGA in pure $\mathrm{CO}_{2}$, the filtration method yields $21.8 \mathrm{mg} \mathrm{g}^{-1}(2.3)$ at $30^{\circ} \mathrm{C}$ whereas the simple impregnation method only exhibits a $\mathrm{CO}_{2}$ uptake of $8.2 \mathrm{mg} \mathrm{g}^{-1}(0.4)$. The corresponding working capacity $\left(30 / 80^{\circ} \mathrm{C}\right)$ 
increased to $10.8 \mathrm{mg} \mathrm{g}^{-1}(0.3)$ from $4.2 \mathrm{mg} \mathrm{g}^{-1}(0.5)$ with the improved impregnation method (numbers in brackets represent the standard error of the mean). Detailed information on the $\mathrm{CO}_{2}$ uptake at different temperatures is shown in Figure S2. For further testings, we used the filtration method to impregnate $\mathrm{SiC}$ fibers with PEI.

The specific $\mathrm{CO}_{2}$ uptake of both fiber types at different temperatures and ambient pressure for pure $\mathrm{CO}_{2}$ and a gas mixture of $15 \mathrm{vol} \% \mathrm{CO}_{2}$ and $85 \mathrm{vol} \% \mathrm{~N}_{2}$ is shown in Figure 4. Both fibers exhibit a decrease in $\mathrm{CO}_{2}$ uptake per gram fiber at increasing temperatures enabling desorption at elevated temperatures. The maximum $\mathrm{CO}_{2}$ uptake for the SiC-PEI fibers is $19.2 \mathrm{mg} \mathrm{g}^{-1}$ under pure $\mathrm{CO}_{2}$ and $8.3 \mathrm{mg} \mathrm{g}^{-1}$ under $15 \mathrm{vol} \% \mathrm{CO}_{2}$ at $30^{\circ} \mathrm{C}$. The CNT-zeolite fibers attain a maximum of $209.6 \mathrm{mg} \mathrm{g}^{-1}$ under pure $\mathrm{CO}_{2}$ and $102.2 \mathrm{mg} \mathrm{g}^{-1}$ under $15 \mathrm{vol} \%$ $\mathrm{CO}_{2}$ at $30^{\circ} \mathrm{C}$. The CNT-zeolite fiber thus shows nearly ten times higher values of adsorbed $\mathrm{CO}_{2}$ per gram fiber than the SiC-PEI fiber. The differences are not only attributed to the different adsorbents zeolite and PEI but also to the different nature and density of the support materials $\mathrm{CNT}$ and $\mathrm{SiC}$. When the $\mathrm{CO}_{2}$ uptake is written in $\mathrm{mg}_{\text {adsorbed }} \mathrm{O}_{2}$ per $\mathrm{g}_{P E I}$, $21.8 \mathrm{mg} / \mathrm{g}_{\mathrm{SiC}-\mathrm{PEIfiber}}$ correspond to $240 \mathrm{mg} / \mathrm{g}_{\text {PEI }}$. The amine efficiency denotes the molar ratio of adsorbed $\mathrm{CO}_{2}$ per amine group $[26,45]$ and is calculated to $0.23 \mathrm{~mol}_{\mathrm{CO}_{2}} / \mathrm{mol}_{\text {amine }}$, which is comparable to data found in literature using low molecular branched PEI [26, 45]. The load of adsorbent material is significantly higher for the CNT-zeolite fiber with $80 \mathrm{wt} \%$ mass share of adsorbent, while the mass share of PEI on the SiC-PEI fiber comprises 9 wt \%. However, altering the coating process, e.g. by using a higher PEI load in the impregnation solution may lead to higher mass shares and, consequently, higher $\mathrm{CO}_{2}$ uptake per $\mathrm{g}_{\mathrm{SiC}-\mathrm{PEIfiber}}$.

The difference in $\mathrm{CO}_{2}$ uptake between $30^{\circ} \mathrm{C}$ and $80^{\circ} \mathrm{C}$ is used as an estimate for the expected $\mathrm{CO}_{2}$ adsorption capacity measured with the module. The respective working ca- 


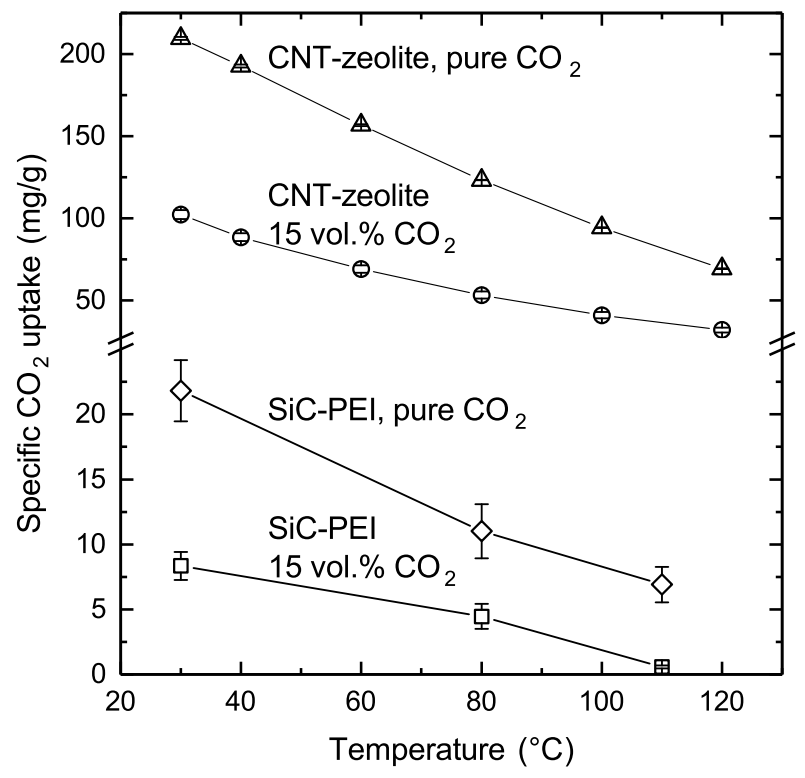

Figure 4: $\mathrm{CO}_{2}$ uptake per gram fiber at different temperatures measured by TGA under pure $\mathrm{CO}_{2}$ or 15 vol. \% $\mathrm{CO}_{2}$ in $\mathrm{N}_{2}$ (error bars represent standard error of the mean of three different fibers).

pacities between $30^{\circ} \mathrm{C}$ and $80^{\circ} \mathrm{C}$ based on Figure 4 amount to $10.8 \mathrm{mg} / \mathrm{g}_{\text {Fiber }}(0.3)$ and $86.3 \mathrm{mg} / \mathrm{g}_{\text {Fiber }}(1.0)$ for pure $\mathrm{CO}_{2}$ on $\mathrm{SiC}-\mathrm{PEI}$ and CNT-zeolite, respectively, and $3.9 \mathrm{mg} / \mathrm{g}_{\text {Fiber }}$ (0.1) and $49 \mathrm{mg} / \mathrm{g}_{\text {Fiber }}(1.7)$ for $15 \mathrm{vol} \% \mathrm{CO}_{2}$ for SiC-PEI and CNT-zeolite, respectively.

TGA measurements not only provide information about the working capacity but also about the kinetics of $\mathrm{CO}_{2}$ adsorption on the fibers at different temperatures. A recent study on the $\mathrm{CO}_{2}$ sorption kinetics on PEI-impregnated porous structures shows that changes in sorption mechanisms and heat of adsorption occur depending on the adsorption temperature [46]. Current research indicates that adsorption of $\mathrm{CO}_{2}$ on PEI-impregnated adsorbents may be an intraparticle- or diffusion-controlled process and analyzing the relation between $\mathrm{CO}_{2}$ pressure and temperature at a given $\mathrm{CO}_{2}$ uptake is inaccurate $[45,47]$. It is also assumed that the physisorbed $\mathrm{CO}_{2}$ is not only in thermodynamic equilibrium with $\mathrm{CO}_{2}$ in the gas phase but also participates directly in the reaction with the immobilized amine, resulting 
in negative activation energies [48]. In this context, we do not want to presume to identify adsorption kinetics, since such complex behavior requires adequate, in-depth measuring methods exceeding the scope of this work.

The kinetics of the CNT-zeolite fibers for three different temperatures $\left(30^{\circ} \mathrm{C}, 50^{\circ} \mathrm{C}\right.$, and $80^{\circ} \mathrm{C}$ ) were fitted by two models: The Avrami model was shown to accurately describe $\mathrm{CO}_{2}$ adsorption on zeolites [49] and the recently proposed dual kinetic model (DKM) [50]. The Avrami model is a fractional kinetic model that describes the behavior of non-catalytic gas-solid reactions [51]. Detailed information and the model equations can be found in the Supporting Information. Experimental data and fits obtained with both models are shown in Figure S6. Both models are able to describe the kinetic behavior of the CNT-zeolite fibers precisely. Since time-dependent kinetics such as the Avrami model are difficult to implement and additionally, the DKM describes the kinetics more accurately (see Figure S6 and the coefficients of determination $\mathrm{R}^{2}$ in Table S3 and S4) the DKM model was used in the simulation.

At higher temperatures $\left(80^{\circ} \mathrm{C}\right)$, the $\mathrm{CO}_{2}$ uptake reaches a plateau-like region with very little increase after approximately $30 \mathrm{~s}$ while the kinetics slow down for decreased temperatures. At $50{ }^{\circ} \mathrm{C}$, the $\mathrm{CO}_{2}$ uptake plateaus at approximately $60 \mathrm{~s}$ while at $30^{\circ} \mathrm{C}$ the uptake curve flattens out after $90 \mathrm{~s}$. The working capacity between $30^{\circ} \mathrm{C}$ and $80^{\circ} \mathrm{C}$ after $90 \mathrm{~s}$ is $45.9 \mathrm{mg} \mathrm{g}^{-1}$ (1.4) and thus, $93.5 \%$ of the working capacity after $45 \mathrm{~min}$ are obtained (see Figure 8). After $3 \mathrm{~min}, 98.7 \%$ of the working capacity after $45 \mathrm{~min}$ is reached $\left(48.4 \mathrm{mg} \mathrm{g}^{-1}\right.$ (1.4)). This indicates the feasibility of short cycle times when using the CNT-zeolite fibers.

The adsorption isotherms measured by pycnometry from 0.004 bar to 1.1 bar are shown in Figure 5a for the SiC-PEI fibers and in Figure 5b for the CNT-zeolite fibers. The SiC-PEI 
fibers exhibit a steep increase in adsorbed $\mathrm{CO}_{2}$ up to approximately 0.05 bar to $5.3 \mathrm{mg} \mathrm{g}^{-1}$ followed by a slower increase to $14.6 \mathrm{mg} \mathrm{g}^{-1}$ at 1.1 bar. The Freundlich isothermal model has been used before to describe the behavior of amine-functionalized sorbents [52]. The Freundlich equation [53]

$$
q_{e}=K_{f} \cdot p_{C O_{2}}^{1 / n}
$$

is an empirical model applicable to nonideal sorption on heterogeneous surfaces as well as multilayer sorption [54]. Here, $\mathrm{q}_{e}$ is the amount of $\mathrm{CO}_{2}$ adsorbed at the partial pressure $\mathrm{p}_{\mathrm{CO}_{2}}$ while $\mathrm{K}_{f}$ and $\mathrm{n}$ are constants of the model. It describes the behavior of the SiC-PEI fibers precisely as shown by the fit in Figure 5a. The model parameters are summarized in Table 3. Since no constant activation energy for a possible Arrhenius approach could be identified, the calculation of higher temperature isotherms requires additional experimental data. A drawback of the Freundlich isothermal model is that it allows indefinite increase in adsorption with pressure [55]. For further studies it could be beneficial to use the LangmuirFreundlich isotherm instead. The steep increase in $\mathrm{CO}_{2}$ uptake at very low partial pressures is in agreement with current literature on PEI adsorption of $\mathrm{CO}_{2}[56]$ and could indicate good applicability of the SiC-PEI fibers for direct capture of $\mathrm{CO}_{2}$ from air where it is currently present at around $400 \mathrm{ppm}$ [57]. The discrepancy in $\mathrm{CO}_{2}$ uptake measured by TGA and pycnometry $\left(19.2 \mathrm{mg} \mathrm{g}^{-1}\right.$ vs. $\left.14.6 \mathrm{mg} \mathrm{g}^{-1}\right)$ are probably due to the isotherm being a single, representative measurement. Furthermore, the equilibrium time is different for each measurement method: TGA data points were calculated after 60 min adsorption time (cf. section 2.3) while the adsorption time for the last data point in the isotherm at 1.1 bar was 
$13 \mathrm{~min}$ (the total adsorption time for the entire isotherm was $11 \mathrm{~h}$ ).

The adsorption isotherm of the zeolite-CNT fibers also shows different gradients but cannot be divided into two sections. No steep increase at very low partial pressures can be observed for the zeolite-CNT fibers. However, zeolites have previously been proposed as sorbents for direct air capture [58]. Isotherms of $\mathrm{CO}_{2}$ adsorption on $\mathrm{NaY}$ zeolites have been found to be best described using the Langmuir isothermal model [59]. The Langmuir equation [60]

$$
q_{e}=\frac{q_{s a t} \cdot K_{L} \cdot P_{C O_{2}}}{1+K_{L} \cdot P_{C O_{2}}}
$$

assumes that adsorption takes place at specific homogeneous sites within the adsorbent and the adsorbent has a finite capacity for the adsorbate i.e., a saturation is reached [61]. Here, $\mathrm{q}_{e}$ is also the amount of $\mathrm{CO}_{2}$ adsorbed at the partial pressure $\mathrm{p}_{\mathrm{CO}_{2}}$ while $\mathrm{q}_{\text {sat }}$ is the amount of $\mathrm{CO}_{2}$ adsorbed at saturation and $\mathrm{K}_{L}$ is a model constant. The fit obtained for the CNT-zeolite adsorption isotherm using the Langmuir equation describes the sorbent's behavior precisely as can be seen in Figure 5b. Thus, a temperature relation can be obtained when considering literature data for the activation energy [62, 63]. The Langmuir constants follow an Arrhenius type approach [64]. The model parameters are summarized in Table 3. A discrepancy between values obtained by TGA and pycnometry may possibly be attributed to different adsorption times to reach equilibrium (45 min for TGA and about 8 min for pycnometry). 
Table 3: Constants for Freundlich and Langmuir isothermal models. $\mathrm{K}_{f}, \mathrm{~K}_{L}$, and $\mathrm{n}$ are model constants, $\mathrm{q}_{\text {sat }}$ denotes the saturation of adsorbed $\mathrm{CO}_{2}$ and $\mathrm{R}^{2}$ is the coefficient of determination.

\begin{tabular}{llll}
\hline & & & \\
Para- & Unit & Freundlich & Langmuir \\
meter & & SiC-PEI & CNT-zeolite \\
\hline & & & \\
$\mathrm{K}_{f}$ & $\mathrm{mmolg}^{-1} \mathrm{~Pa}^{-1}$ & 0.0104 & \\
$\mathrm{n}$ & - & 3.4208 & \\
$\mathrm{~K}_{L}$ & $\mathrm{~Pa}^{-1}$ & & $4.7 \cdot 10^{-5}$ \\
$\mathrm{q}_{\text {sat }}$ & $\mathrm{mmolg}^{-1}$ & & 3.722 \\
$\mathrm{R}^{2}$ & - & 0.98 & 0.99 \\
\hline
\end{tabular}




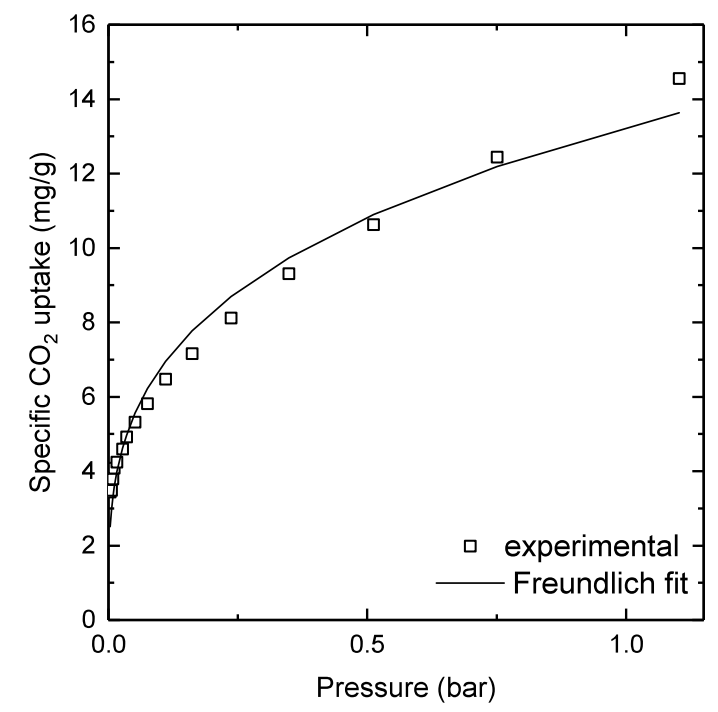

(a) SiC-PEI fibers. Data fitted with the Freundlich model.

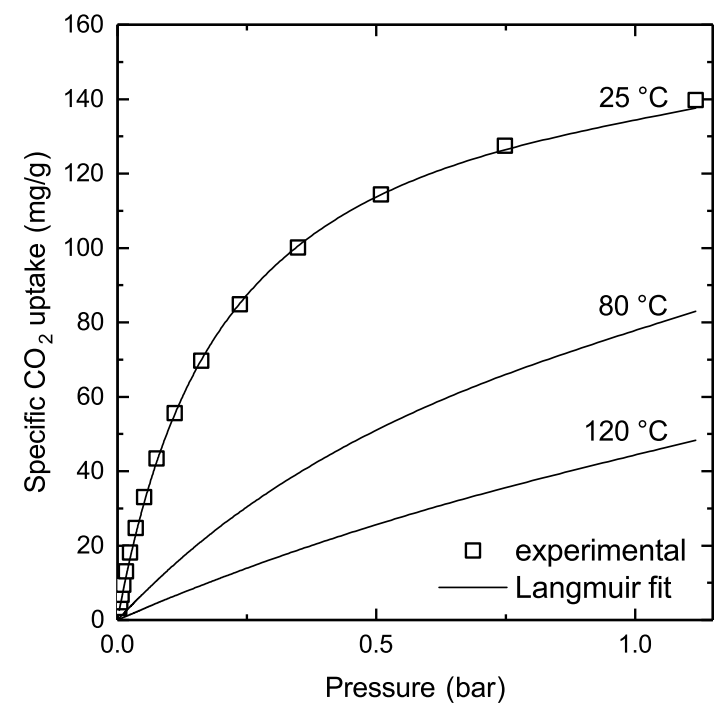

(b) CNT-zeolite fibers. Data fitted with the Langmuir model.

Figure 5: Adsorption isotherm for both fiber types measured by pycnometry at ambient temperature and at higher temperatures for CNT-zeolite to be used in the simulation. Symbols represent experimental data while the lines represent a fit of that data. 


\subsection{Module design}

We designed a gas-tight, electrically connectable lab scale module to test a bundle of 15 fibers in a proof-of-concept electric swing adsorption process. The module is made of aluminum and consists of two parts: the lower part contains a chamber for the fibers with electrical connections to a voltage source. The fiber chamber features a pressure and a temperature sensor and owns a gas inlet and outlet channel. A schematic drawing of the lower part can be found in the Supporting Information (Figure S4). The upper part serves as a lid to seal the fiber chamber squeezing a flat gasket between the upper and the lower part with twelve screws. To avoid a short-circuit between the fiber bundle and the module, two small pieces of rubber are placed under the wires. Temperature and pressure sensor are connected with push-in fittings with cylindrical threads to be gas-tight. To prove gas tightness of the module, the module was pressurized stepwise to 1,2 and 3 bar with each step lasting at least $30 \mathrm{~min}$. The pressure was monitored and the module was checked for gas bubbles under water. Figure 6 shows a fiber bundle of the SiC-PEI fibers in the fiber chamber of the module with attached electrical connections, a pressure sensor, and a temperature sensor.

\subsection{ESA on fiber bundles}

The module was used to test the electrical heatability of the fibers and to determine the working capacity of a fiber bundle between $30^{\circ} \mathrm{C}$ and $80^{\circ} \mathrm{C}$ using pure $\mathrm{CO}_{2}$. When the fiber bundle was placed in the module, it was ensured that the temperature sensor touches the module. Under applied voltage both fiber types heat up and their temperature reaches a plateau at approximately $80^{\circ} \mathrm{C}$ after $30 \mathrm{~s}$, see Figure 7 . The temperature remains stable for the course of the measurement (15 min). 


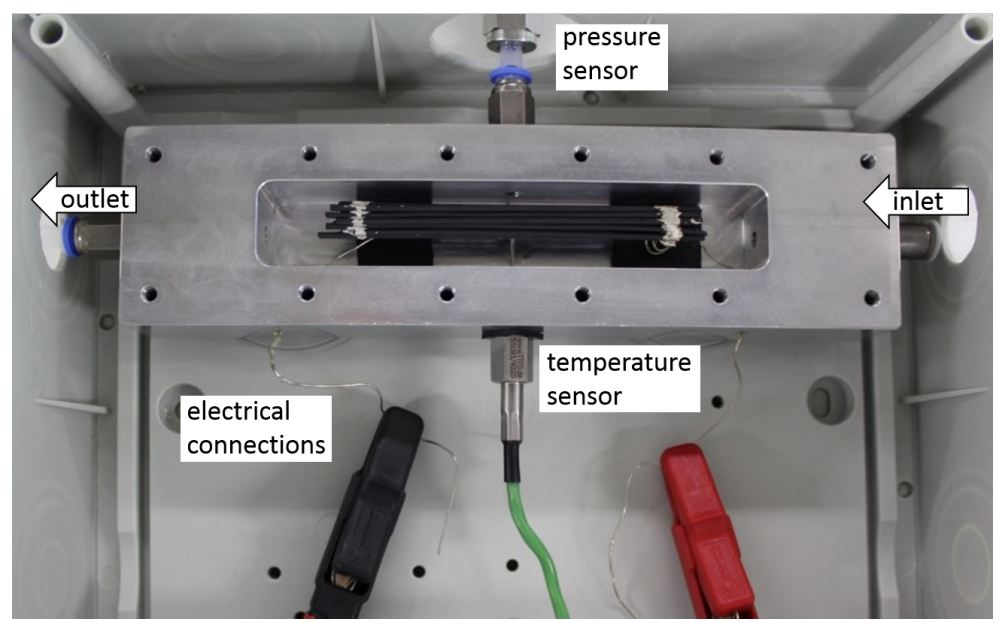

Figure 6: Open fiber chamber of the aluminum module containing a bundle of SiC-PEI fibers with electrical connections as well as a pressure and a temperature sensor.

The working capacity of the two fiber types determined via different measurement methods can be seen in Figure 8. External heating means the "conventional" heating of the entire module in an oven while internal heating describes the direct heating of the fiber bundle using the Joule effect. Comparing both heating approaches enables testing the feasibility of Joule heating of the bundle. For both the SiC-PEI and the CNT-zeolite fibers, the working capacity measured with the module decreases slightly compared to the capacity measured with TGA, independent of the heating method within the module. The decrease can be attributed to the fact that no degas step was performed prior to the module experiments. Thus, both materials are expected to have residual water or gas adsorbed that might influence the results. Both fiber types yield similar adsorption capacities for external and internal heating, respectively. This emphasizes the feasibility of electrical heating for these fibers as a desorption strategy in a module configuration. 


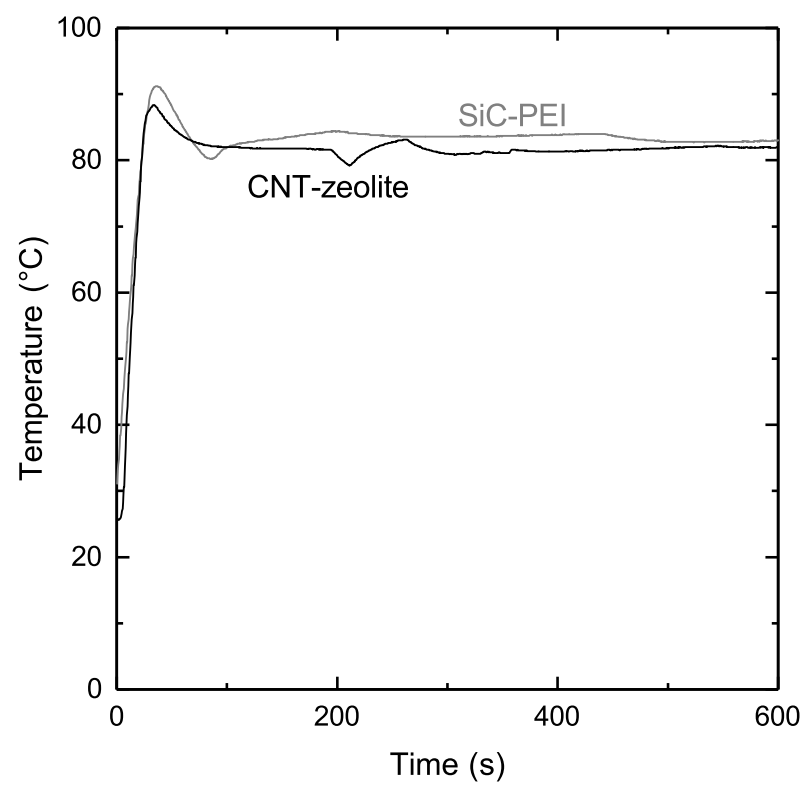

Figure 7: Temperature course of a SiC-PEI and a CNT-zeolite fiber bundle in the module recorded during an internal heating measurement.

\subsection{Energy efficiency}

To compare the two composite fibers with respect to their energy demand, Table 4 lists the energy requirement for heating the fibers from $30^{\circ} \mathrm{C}$ to $80^{\circ} \mathrm{C}$. The energy demand comprises only the demand for heating calculated from the recorded voltage and current during the heat-up phase. The latent heat of adsorption was not considered since we aim at comparing the heating efficiency of the fibers independent of the two different latent heat demands. The energy demand is calculated with respect to the adsorbed amount of $\mathrm{CO}_{2}$ measured with TGA according to the following equation

$$
Q_{\text {rel }}=\frac{P_{\Delta 50^{\circ} \mathrm{C}}}{m_{\text {fibers }} \cdot \Delta q_{\Delta 50^{\circ} \mathrm{C}}}\left(\mathrm{MJ} / \mathrm{kg}_{\mathrm{CO}_{2}}\right)
$$

where $P$ is the sum of the applied power measured in intervals of $0.4 \mathrm{~s}$ during the time of heating from $30^{\circ} \mathrm{C}$ to $80^{\circ} \mathrm{C}, m_{\text {fibers }}$ is the mass of the fiber bundle, and $\Delta q_{\Delta 50^{\circ} \mathrm{C}}$ the working 


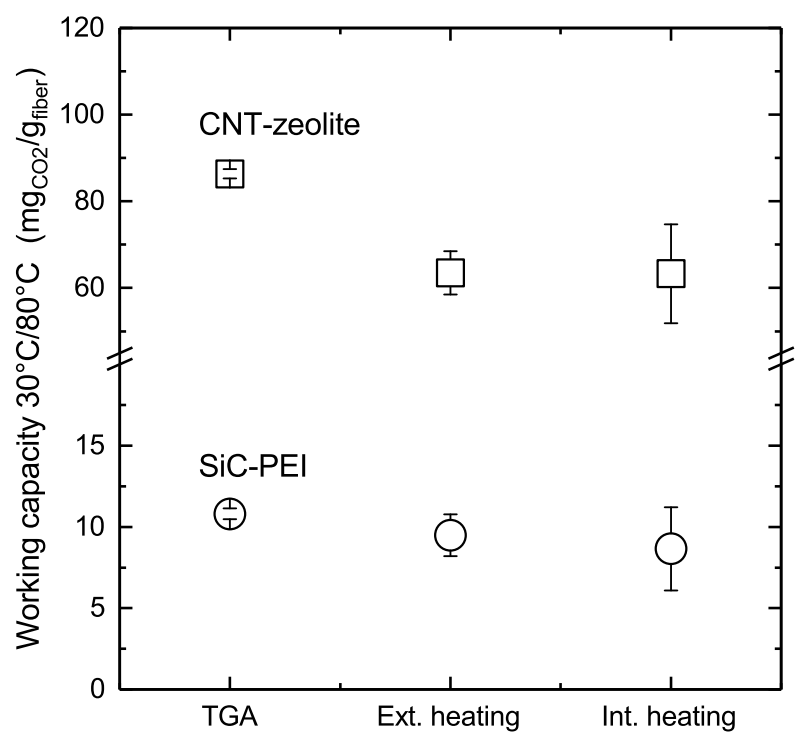

Figure 8: Working capacity of the two different fiber types between $30^{\circ} \mathrm{C}$ and $80^{\circ} \mathrm{C}$ measured with TGA and with fiber bundles in the module using external and internal (electrical) heating. The y-axis is split. The error bars represent the standard error of the mean of three different fibers (TGA) or three different measurements with two different fiber bundles (module measurements).

capacity of $\mathrm{CO}_{2}$ between $30^{\circ} \mathrm{C}$ and $80^{\circ} \mathrm{C}$ gained from TGA measurements in $\left(\mathrm{mg} / \mathrm{g}_{\text {fiber }}\right)$.

While the two fiber types deviate in their mass related adsorption capacities nearly by a factor of $10\left(10.8 \mathrm{mg} / \mathrm{g}_{\mathrm{SiC}-\mathrm{PEI}, \mathrm{fiber}} \mathrm{vs} .86 .3 \mathrm{mg} / \mathrm{g}_{\mathrm{CNT}-\text { zeolite,fiber }}\right)$, the required energy demands per $\mathrm{kg}_{\mathrm{CO}_{2}}$ are in the same order of magnitude with CNT-zeolite being somewhat more effective. However, the mass share of PEI on $\mathrm{SiC}$ is still comparably low and may be improved with higher PEI contents in the coating solution. To conclude, with two different approaches of composite fibers for ESA application a comparable energy requirement is reached. The heating time required to reach $80^{\circ} \mathrm{C}$ is approximately $25-30 \mathrm{~s}$ which is significantly faster than conventional heating [8]. Improved electrical connections could lead to an additional decrease in heating time and energy demand. 
Table 4: Energy demand of the composite fibers measured at the fiber bundle. Time denotes the time required to reach $80^{\circ} \mathrm{C}$. Values in brackets represent the standard error of the mean.

\begin{tabular}{cccc} 
Parameter & Unit & SiC-PEI & CNT-zeolite \\
\hline$Q_{\text {rel }}$ & $\mathrm{J} /\left(\mathrm{g}_{\text {Fiber }} \mathrm{K}\right)$ & $3.1(0.5)$ & $15.8(1.9)$ \\
$Q_{\text {rel }}$ & $\mathrm{MJ} / \mathrm{kg}_{\mathrm{CO}_{2}}$ & $14.5(2.3)$ & $9.2(1.1)$ \\
Time & $\mathrm{s}$ & $29.8(3.9)$ & $24.7(0.8)$ \\
\hline
\end{tabular}

\subsection{Mathematical modelling}

To estimate the performance of our hybrid hollow fibers on a process level a mathematical model was established. The mathematical model is intended as a first indicator for the applicability of our fibers in a process. The model was thus implemented without optimization and only for CNT-zeolite fibers as they show a better performance compared with SiC-PEI. Since the equilibrium (Figure 5b) and kinetic (Figure S6) models of the CNT-zeolite fibers showed good accordance with experimental data, breakthrough, ad- and desorption cycles as well as general process behavior can be investigated.

Adsorption breakthrough curves were simulated for adsorption conditions of $25^{\circ} \mathrm{C}$ and 1 bar. The molar $\mathrm{CO}_{2}$ fraction in the gaseous phase at the column outlet is plotted over time in Figure 9. For the operating conditions of the reference case (cf. Table S2), $\mathrm{CO}_{2}$ breakthrough occurs after 200 seconds when the fiber bundle was degassed completely prior to the adsorption step. For the steady-state process mode remaining gas with a $\mathrm{CO}_{2}$ molar fraction of 11-15\% from the preceding desorption and regeneration step exits the column outlet due to new feed flow. With desorption conditions of $140^{\circ} \mathrm{C}$ and 0.5 bar a breakthrough 
of the newly fed $\mathrm{CO}_{2}$ occurs after 130 seconds. More complex modes of operation could lead to higher separation efficiency. For instance, Grande et al. [65, 66] presented a seven-step cycle and later a six-step cycle including internal rinsing and purging with recovered gas to improve the enrichment of $\mathrm{CO}_{2}$, doubling the enrichment factor compared to a four-step cycle.

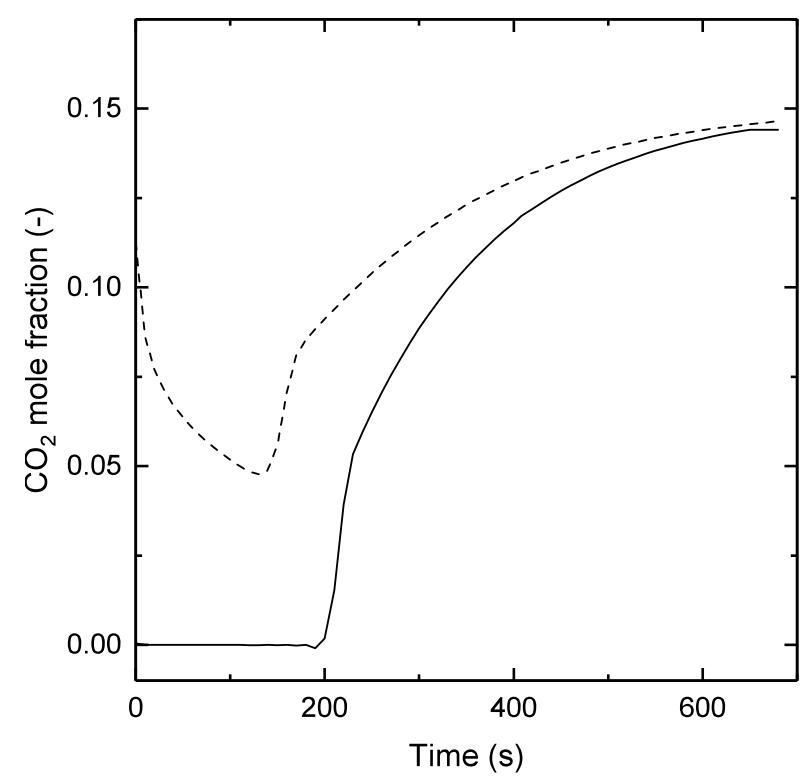

Figure 9: Modelled adsorption breakthrough curve for $\mathrm{CO}_{2}$ adsorption (gas composition: $15 \mathrm{vol} \% \mathrm{CO}_{2}$ in $\mathrm{N}_{2}$ ) on a CNT-zeolite fiber bundle at $25^{\circ} \mathrm{C}$ and ambient pressure. The solid line represents the $\mathrm{CO}_{2}$ molar fraction in the gaseous phase at the column outlet $\mathrm{L}=0.3 \mathrm{~m}$ for a completely degassed column while the dashed line depicts the breakthrough behavior in steady-state.

Figure 10 shows three full cycles of electric swing adsorption on a CNT-zeolite fiber bundle according to the reference case conditions (cf. Table S2) and a desorption temperature and pressure of $140^{\circ} \mathrm{C}$ and 0.5 bar. The solid line represents the loading of the sorbent material at $1 / 3$ length of the fiber bundle while the dashed line depicts the loading at $2 / 3$ length. At $1 / 3$ length of the fiber module, the loading rises monotonically from about $20 \mathrm{mg} \mathrm{g}^{-1}$ to 
its maximum of $65 \mathrm{mg} \mathrm{g}^{-1}$ in $350 \mathrm{~s}$ during the adsorption step. The loading at $2 / 3$ length follows a similar course, resulting in a maximum of $55 \mathrm{mg} \mathrm{g}^{-1}$. Subsequently, the desorption is initiated resulting in a sharp drop to a loading of $22 \mathrm{mg} \mathrm{g}^{-1}$, which leads to a working capacity of more than $30 \mathrm{mg} \mathrm{g}^{-1}$. The difference in working capacity calculated with the model and measured with the module (cf. Figure 8) results from the difference in $\mathrm{CO}_{2}$ concentration during adsorption (15 vol \% vs. 100\%) and from the different desorption strategies. After the desorption step of $80 \mathrm{~s}$, the column is cooled and pressurized to ambient conditions for $350 \mathrm{~s}$. Here, an appreciable difference between the two locations of the bundle manifests, which can be explained by a heterogeneous temperature and concentration profile along the fiber length in the closed column. Lower temperatures and higher $\mathrm{CO}_{2}$ partial pressure temporarily lead to a higher loading in the rear part of the column. The next adsorption step then starts with a slight decrease in loading due to the entering feed gas diluting the residual $\mathrm{CO}_{2}$-rich gas phase from the previous desorption step.

To examine the viability of CNT-zeolite fibers for the process described above, different operating points are simulated to calculate minimum energy requirements per $\mathrm{kg} \mathrm{CO}_{2}$ produced and the respective throughput as shown in Figure 11. The influence of different desorption temperatures and pressures on the process performance were simulated and analyzed. The best process performance was achieved when applying a low vacuum pressure of 0.2 bar, enhancing both $\mathrm{CO}_{2}$ desorption with a throughput of $8.4 \times 10^{-3} \mathrm{~kg} \mathrm{~h}^{-1}$ and its transport out of the column/bundle, resulting in an MER of $9 \mathrm{MJ} / \mathrm{kg}_{\mathrm{CO}_{2}}$ at $100{ }^{\circ} \mathrm{C}$. Due to fast pressure decrease and low pressure vacuum, the MER is almost constant over the presented temperature range, meaning that most of the product gas is recovered by pressure equilibrium. In contrast, when desorbing at ambient pressure a nearly linear temperature 


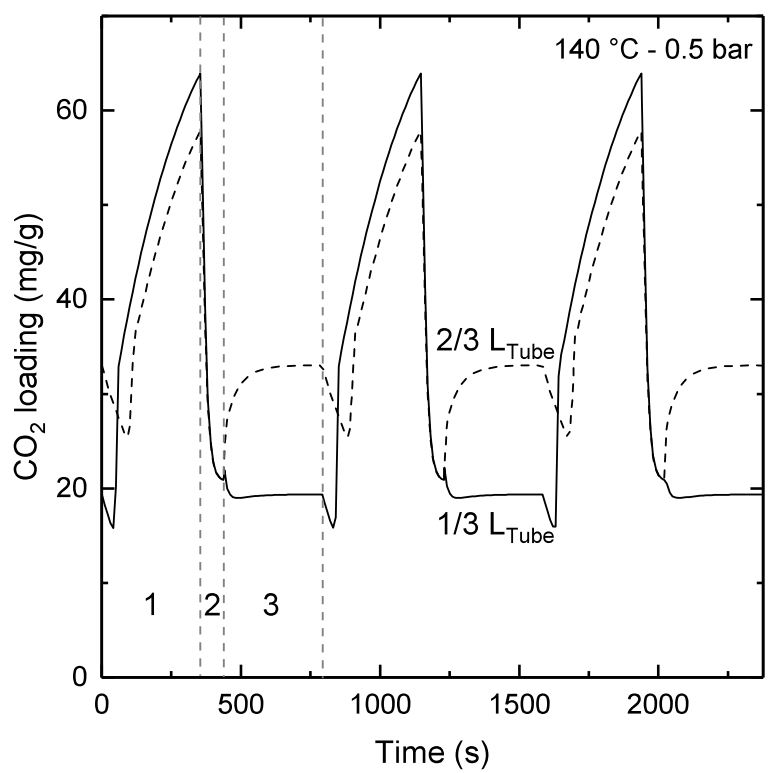

Figure 10: Modelled ad- and desorption cycles for $\mathrm{CO}_{2}$ adsorption (gas composition: 15 vol $\% \mathrm{CO}_{2}$ in $\mathrm{N}_{2}$ ) on a CNT-zeolite fiber bundle. 1 denotes the adsorption step at ambient conditions, 2 the desorption step, which takes place at $140^{\circ} \mathrm{C}$ and a partial vacuum of 0.5 bar, and 3 the cooling and regeneration step to reach ambient conditions again. The solid line curve represents the adsorbent loading at $1 / 3$ length and the dashed line at $2 / 3$ length of the fiber bundle.

dependency is seen, decreasing from about $65 \mathrm{MJ} / \mathrm{kg}_{\mathrm{CO}_{2}}$ at $100^{\circ} \mathrm{C}$ to $35 \mathrm{MJ} / \mathrm{kg}_{\mathrm{CO}_{2}}$ at $140^{\circ} \mathrm{C}$, showing a reduction in energy requirements of $50 \%$. Here, the increment of the throughput of $40 \%$ between $100^{\circ} \mathrm{C}$ and $140^{\circ} \mathrm{C}$ shows a high potential for an application in TSA. For medium vacuum pressure operation at 0.5 bar and 0.7 bar, energy requirements are $22 \mathrm{MJ} / \mathrm{kg}_{\mathrm{CO}_{2}}$ and $29 \mathrm{MJ} / \mathrm{kg}_{\mathrm{CO}_{2}}$ at $100{ }^{\circ} \mathrm{C}$, respectively, and $18 \mathrm{MJ} / \mathrm{kg}_{\mathrm{CO}_{2}}$ and $19 \mathrm{MJ} / \mathrm{kg}_{\mathrm{CO}_{2}}$ at $140{ }^{\circ} \mathrm{C}$, respectively. When operating at vacuum pressures below 0.5 bar, high temperature operation becomes more energy intensive since the vacuum recovers most of the adsorbate.

Other simulation studies on ESA processes show lower energy requirements than the ones reported here. For instance, Lillia et al. [67] calculated an energy requirement of 
$2.86 \mathrm{MJ} / \mathrm{kg}_{\mathrm{CO}_{2}}$ when capturing $\mathrm{CO}_{2}$ from a stream containing $12 \mathrm{wt} \% \mathrm{CO}_{2}$ using a $13 \mathrm{X}$ zeolite / activated carbon hybrid material and an eight step cycle. Using a hypothetical adsorbent made from zeolites and graphite and adsorbing from a gas mixture with low $\mathrm{CO}_{2}$ content (3.5\%), representing flue gas from a natural gas power plant, Grande et al. [65] simulated a five step ESA cycle requiring $2.04 \mathrm{MJ} / \mathrm{kg}_{\mathrm{CO}_{2}}$. Obviously, the energy requirement calculated in our work exceeds these values. However, as stated before, our model is intended as a first indicator of the applicability of our fibers in a process and does not include any optimization. Different measures will lead to a decreased energy requirements. For instance, a more sophisticated process design should lead to a 50 to $60 \%$ reduction of the MER as reported by Grande et al. [66]. Additional optimization of the geometry and the fiber composition could lead to even lower energy demands. Additional approaches to improve the process model are discussed at the end of this section. 


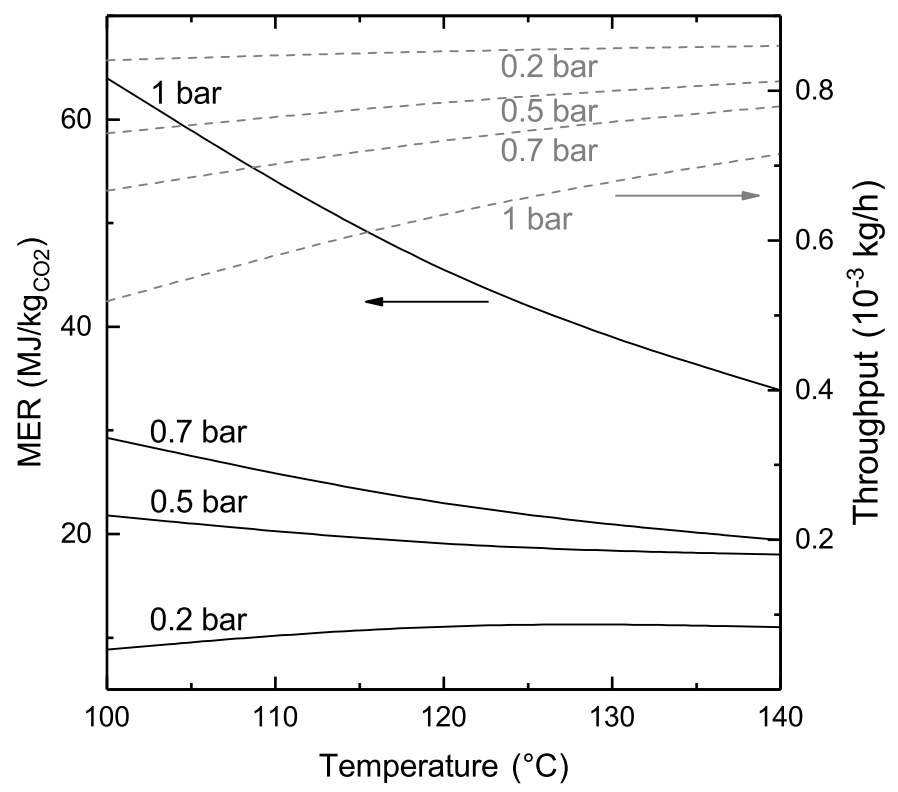

Figure 11: Minimal energy requirement per $\mathrm{kg}_{\mathrm{CO}_{2}}$ for the ESA process at different operating points. The column was fully loaded every cycle and subsequently regenerated to its respective temperature and pressure equilibrium.

Low energy requirements are not the only advantage resulting from high temperature or low temperature plus low pressure operation. As presented in Figure 12, the product gas purity can be increased from $45 \%$ at $100^{\circ} \mathrm{C}$ to $65 \%$ at $140{ }^{\circ} \mathrm{C}$ using the simple process configuration described above at ambient pressure. For medium vacuum pressures, the $\mathrm{CO}_{2}$ purity improves from $63 \%$ to $75 \%$ in the same temperature range. Even higher purities can be achieved when applying a low pressure vacuum of 0.2 bar, resulting in a maximum purity of $81 \%$ at $140{ }^{\circ} \mathrm{C}$ and a promising enrichment factor of 5.4 for $\mathrm{CO}_{2}$. In order to reach such high purities in a three step TSA process, the column must be loaded to its maxiumum, since desorbed $\mathrm{CO}_{2}$ will be mixed with remaining $\mathrm{N}_{2}$ in the gaseous phase. This also means that the column must be fed even after $\mathrm{CO}_{2}$ breakthrough at the outlet, resulting in lower recoveries (see Figure S5). For ambient pressure, $\mathrm{CO}_{2}$ recovery is $21 \%$ at $100{ }^{\circ} \mathrm{C}$ increasing 
to $32 \%$ at $140{ }^{\circ} \mathrm{C}$ and when applying low pressure vacuum up to $62 \%$ at $140{ }^{\circ} \mathrm{C}$, for the fully loaded column.

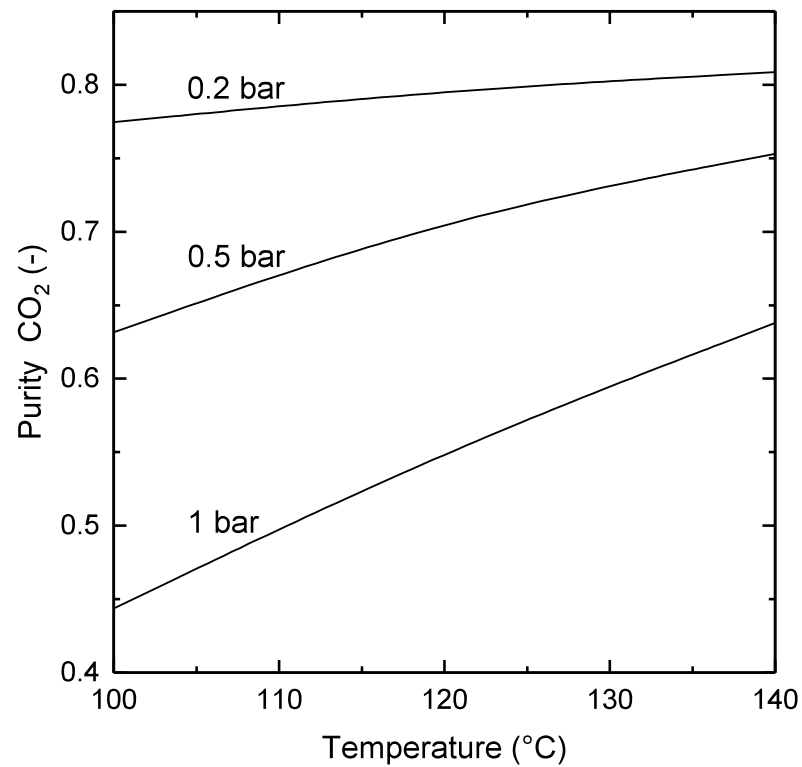

Figure 12: $\mathrm{CO}_{2}$ purity in product stream for different operating points. The column was fully loaded in every cycle and subsequently regenerated to its respective temperature and pressure equilibrium.

Overall, the results of the mathematical modelling prove the viability of our hollow fibers for ESA processes and indicate the optimization potential of the proposed model process conditions. Considering the results in terms of process development, future research should engage in more complex process design, optimization of fiber/bundle geometry and the identification of the capital cost trade-offs that relate to vacuum operation at high volume flows. Especially internal rinsing with recovered $\mathrm{CO}_{2}$ and suitable purge steps are conceivable options to enhance energy demand, purity, and recovery. 


\section{Conclusion}

Carbon capture remains one of the imperative measures to mitigate climate change and it necessitates research efforts. We presented two different hollow fiber types potentially suitable for $\mathrm{CO}_{2}$ capture in an electrical swing adsorption process. Silicon carbide fibers were impregnated with PEI (SiC-PEI) while the other fiber type consisted of a carbon nanotube framework with embedded zeolite particles (CNT-zeolite). The adsorption capacity between $30{ }^{\circ} \mathrm{C}$ and $80^{\circ} \mathrm{C}$ measured with TGA and a gas mixture with 15 vol $\% \mathrm{CO}_{2}$ in $\mathrm{N}_{2}$

was $3.9 \mathrm{mg} / \mathrm{g}_{\text {Fiber }}(0.1)$ and $49 \mathrm{mg} / \mathrm{g}_{\text {Fiber }}$ (1.7) for SiC-PEI and CNT-zeolite, respectively. Higher capacities of the SiC-PEI fibers could be achieved by higher PEI loadings. Experiments with a bundle of 15 fibers in a module proved the electrical heatability of the fibers where $80^{\circ} \mathrm{C}$ were reached within less than $30 \mathrm{~s}$ independent of the fiber type. The energy demand for heating was $14.5 \mathrm{MJ} / \mathrm{kg}_{\mathrm{CO}_{2}}(2.3)$ and $9.2 \mathrm{MJ} / \mathrm{kg}_{\mathrm{CO}_{2}}(1.1)$ for the SiC-PEI and the CNT-zeolite fibers, respectively. Better electrical connections could improve both the heating time and the energy demand. Adsorption experiments with the module yielded similar $\mathrm{CO}_{2}$ adsorption capacities compared to the TGA measurements. The applicability of our hollow fibers for electrical swing adsorption was thus successfully demonstrated in a proof-of-concept module. Mathematical modelling of an ESA process with the CNT-zeolite fibers resulted in promising $\mathrm{CO}_{2}$ purities of $81 \%$ when applying vacuum in the desorption step in addition to the temperature increase. Short cycle times of less than 500 s were needed to achieve working capacities of $40 \mathrm{mg} / \mathrm{g}_{\text {Fiber }}$. 


\section{Acknowledgement}

The authors thank P. de Wit and N. Benes (University of Twente) for providing the hollow fiber membranes to produce the silicon carbide sorbent. M.W. acknowledges the support through an Alexander-von-Humboldt Professorship. This work was performed in part at the Center for Chemical Polymer Technology CPT, which is supported by the EU and the federal state of North Rhine-Westphalia (grant no. EFRE 3000883 02).

\section{References}

[1] D. Bathen, M. Breitbach, Adsorptionstechnik, Springer Berlin Heidelberg, Berlin, Heidelberg, 2001. doi:10.1007/978-3-642-18235-8.

[2] C. A. Grande, R. P. Ribeiro, A. E. Rodrigues, Challenges of electric swing adsorption for $\mathrm{CO}_{2}$ capture, ChemSusChem 3 (2010) 892-898.

[3] T. S. Lee, J. H. Cho, S. H. Chi, Carbon dioxide removal using carbon monolith as electric swing adsorption to improve indoor air quality, Building and Environment 92 (2015) 209-221.

[4] W. Choi, K. Min, C. Kim, Y. S. Ko, J. W. Jeon, H. Seo, Y. K. Park, M. Choi, Epoxide-functionalization of polyethyleneimine for synthesis of stable carbon dioxide adsorbent in temperature swing adsorption, Nature Communications 7 (2016) 12640. doi:10.1038/ncomms12640.

[5] F. Su, C. Lu, $\mathrm{CO}_{2}$ capture from gas stream by zeolite $13 \mathrm{X}$ using a dual-column temperature/vacuum swing adsorption, Energy and Environmental Science 5 (2012) 9021-9027. doi:10.1039/c2ee22647b. 
[6] V. Masson-Delmotte, P. Zhai, H. O. Pörtner, D. Roberts, J. Skea, P. R. Shukla, A. Pirani, W. Moufouma-Okia, C. Péan, R. Pidcock, S. Connors, J. B. R. Matthews, Y. Chen, X. Zhou, M. I. Gomis, E. Lonnoy, T. M. amd M. Tignor, T. Waterfield, IPCC Summary for Policymakers, World Meteorological Organization, Geneva, Switzerland, 2018.

[7] F. Salvador, N. Martin-Sanchez, R. Sanchez-Hernandez, M. J. Sanchez-Montero, C. Izquierdo, Regeneration of carbonaceous adsorbents. Part I: Thermal Regeneration, Microporous and Mesoporous Materials 202 (2015) 259-276. doi:10.1016/j.micromeso.2014.02.045.

[8] R. Ribeiro, C. Grande, A. Rodrigues, Electric swing adsorption for gas separation and purification: a review, Separation Science and Technology 49 (2014) 1985-2002.

[9] C. Cavalcante, Industrial adsorption separation processes: Fundamentals, modeling and applications, Latin American Applied Research 30 (2000) 357-364.

[10] M. Petkovska, D. Tondeur, G. Grevillot, J. Granger, M. Mitrović, Temperature-Swing Gas Separation with Electrothermal Desorption Step, Separation Science and Technology 26 (1991) 425-444. doi:10.1080/01496399108050482.

[11] F. Moskal, J. Nastaj, Internal heat source capacity at inductive heating in desorption step of etsa process, International communications in heat and mass transfer 34 (2007) $579-586$.

[12] J. Reuß, D. Bathen, H. Schmidt-Traub, Desorption by microwaves: mechanisms of multicomponent mixtures, Chemical Engineering \& Technology 25 (2002) 381-384. 
[13] Z. Hashisho, M. Rood, L. Botich, Microwave-swing adsorption to capture and recover vapors from air streams with activated carbon fiber cloth, Environmental Science \& Technology 39 (2005) 6851-6859.

[14] P. D. Sullivan, M. J. Rood, G. Grevillot, J. D. Wander, K. J. Hay, Activated carbon fiber cloth electrothermal swing adsorption system, Environmental Science \& Technology 38 (2004) 4865-4877.

[15] H. An, B. Feng, Desorption of $\mathrm{CO}_{2}$ from activated carbon fibre-phenolic resin composite by electrothermal effect, International Journal of Greenhouse Gas Control 4 (2010) 5763.

[16] C.-H. Yu, C.-H. Huang, C.-S. Tan, A Review of $\mathrm{CO}_{2}$ Capture by Absorption and Adsorption, Aerosol and Air Quality Research 12 (2012) 745-769. doi:10.4209/aaqr.2012.05.0132.

[17] T. Burchell, R. Judkins, A novel carbon fiber based material and separation technology, Energy Conversion and Management 38 (1997) S99-S104.

[18] S. Moon, J. Shim, A novel process for $\mathrm{CO}_{2} / \mathrm{CH}_{4}$ gas separation on activated carbon fibers - electric swing adsorption, Journal of Colloid and Interface Science 298 (2006) $523-528$.

[19] F. Yu, L. A. Luo, G. Grevillot, Electrothermal Desorption Using Joule Effect on an Activated Carbon Monolith, Journal of Environmental Engineering 130 (2004) 242-248.

[20] R. Ribeiro, C. Grande, A. Rodrigues, Electrothermal performance of an activated carbon honeycomb monolith, Chemical Engineering Research and Design 90 (2012) 2013-2022. 
[21] M. J. Regufe, A. F. P. Ferreira, J. M. Loureiro, Y. Shi, A. Rodrigues, A. M. Ribeiro, New hybrid composite honeycomb monolith with 13x zeolite and activated carbon for $\mathrm{CO}_{2}$ capture, Adsorption 24 (2018) 249-265. doi:10.1007/s10450-018-9938-1.

[22] M. J. Regufe, A. F. Ferreira, J. M. Loureiro, A. Rodrigues, A. M. Ribeiro, Electrical conductive 3d-printed monolith adsorbent for $\mathrm{CO}_{2}$ capture, Microporous and Mesoporous Materials 278 (2019) 403-413. doi:10.1016/j.micromeso.2019.01.009.

[23] R. Sevanthi, F. Irin, D. Parviza, W. Jackson, M. Green, Electrical current stimulated desorption of carbon dioxide adsorbed on graphene based structures, RSC Adv. 6 (2016) $43401-43407$.

[24] S. D. Hojniak, A. L. Khan, O. Hollóczki, B. Kirchner, I. F. J. Vankelecom, W. Dehaen, K. Binnemans, Separation of carbon dioxide from nitrogen or methane by supported ionic liquid membranes (silms): Influence of the cation charge of the ionic liquid, The Journal of Physical Chemistry B 117 (2013) 15131-15140.

[25] A. Abdollahi Govar, A. D. Ebner, J. A. Ritter, Effect of $\mathrm{H}_{2} \mathrm{O}$ Vapor on the Adsorption and Desorption Behavior of $\mathrm{CO}_{2}$ in a Solid Amine Sorbent, Energy and Fuels 30 (2016) 10653-10660.

[26] Z. Zhang, X. Ma, D. Wang, C. Song, Y. Wang, Development of silica-gel-supported polyethylenimine sorbents for $\mathrm{CO}_{2}$ capture from flue gas, AIChE Journal 58 (2012) $2495-2502$.

[27] M. L. Gray, J. S. Hoffman, D. C. Hreha, D. J. Fauth, S. W. Hedges, K. J. Champagne, 
H. W. Pennline, Parametric study of solid amine sorbents for the capture of carbon dioxide, Energy \& Fuels 23 (2009) 4840-4844.

[28] R. Veneman, N. Frigka, W. Zhao, Z. Li, S. Kersten, W. Brilman, Adsorption of $\mathrm{H}_{2} \mathrm{O}$ and $\mathrm{CO}_{2}$ on supported amine sorbents, International Journal of Greenhouse Gas Control 41 (2015) $268-275$.

[29] F. Akhtar, Q. Liu, N. Hedin, L. Bergström, Strong and binder free structured zeolite sorbents with very high $\mathrm{CO}_{2}$-over- $\mathrm{N}_{2}$ selectivities and high capacities to adsorb $\mathrm{CO}_{2}$ rapidly, Energy and Environmental Science 5 (2012) 7664-7673. doi:10.1039/c2ee21153j.

[30] P. J. E. Harlick, A. Sayari, Applications of pore-expanded mesoporous silica. 5. triamine grafted material with exceptional $\mathrm{CO}_{2}$ dynamic and equilibrium adsorption performance, Industrial and Engineering Chemistry Research 46 (2007) 446-458. doi:10.1021/ie060774+.

[31] S. Choi, J. H. Drese, C. W. Jones, Adsorbent materials for carbon dioxide capture from large anthropogenic point sources, ChemSusChem 2 (2009) 796-854. doi:10.1002/cssc.200900036.

[32] G. E. Keller, R. A. Anderson, C. M. Yon, R. W. Rousseau, Handbook of separation process technology, JohnWiley, New York (1987).

[33] V. Feng, C. Y. Pan, C. W. McMinis, J. Ivory, D. Gosh, Hollow-fiber-based adsorbers for gas separation by pressure-swing adsorption, AIChE Journal 44 (1998) 1555-1562.

[34] M. E. Avramescu, M. Girones, Z. Borneman, M. Wessling, Preparation of mixed matrix 
adsorber membranes for protein recovery, Journal of Membrane Science 218 (2003) 219 $-233$.

[35] R. Lively, R. R. Chance, W. J. Koros, H. Deckman, B. T. Kelley, Sorbent fiber compositions and methods of temperature swing adsorption, 2012. US Patent 8,133,308.

[36] L. Keller, B. Ohs, J. Lenhart, L. Abduly, P. Blanke, M. Wessling, High capacity polyethylenimine impregnated microtubes made of carbon nanotubes for $\mathrm{CO}_{2}$ capture, Carbon 126 (2018) 338-345. doi:10.1016/j.carbon.2017.10.023.

[37] L. Keller, B. Ohs, L. Abduly, M. Wessling, Carbon nanotube silica composite hollow fibers impregnated with polyethylenimine for $\mathrm{CO}_{2}$ capture, Chemical Engineering Journal 359 (2019) 476-484. doi:10.1016/j.cej.2018.11.100.

[38] P. de Wit, E. J. Kappert, T. Lohaus, M. Wessling, A. Nijmeijer, N. E. Benes, Highly permeable and mechanically robust silicon carbide hollow fiber membranes, Journal of Membrane Science 475 (2015) 480-487.

[39] X. Xu, C. Song, J. M. Andrésen, B. G. Miller, A. W. Scaroni, Preparation and characterization of novel $\mathrm{CO}_{2}$ "molecular basket" adsorbents based on polymer-modified mesoporous molecular sieve MCM-41, Microporous and Mesoporous Materials 62 (2003) 29-45. doi:10.1016/S1387-1811(03)00388-3.

[40] Y. Gendel, O. David, M. Wessling, Microtubes made of carbon nanotubes, Carbon 68 (2014) 818-820.

[41] T. C. Drage, A. Arenillas, K. M. Smith, C. E. Snape, Thermal stability of polyethylenimine based carbon dioxide adsorbents and its influence on selection of 
regeneration strategies, Microporous and Mesoporous Materials 116 (2008) 504-512. doi:10.1016/j.micromeso.2008.05.009.

[42] L. C. Young, B. Finlayson, Mathematical modeling of the monolith converter, Advances in Chemistry Series 133 (1974) 629-643.

[43] F. M. Orr, Jr., $\mathrm{CO}_{2}$ capture and storage: are we ready?, Energy \& Environmental Science 2 (2009) 449-458. doi:10.1039/b822107n.

[44] A. R. Kulkarni, D. S. Sholl, Analysis of equilibrium-based TSA processes for direct capture of $\mathrm{CO}_{2}$ from air, Industrial \& Engineering Chemistry Research 51 (2012) 86318645. doi:10.1021/ie300691c.

[45] F. Liu, K. Huang, C.-J. Yoo, C. Okonkwo, D.-J. Tao, C. W. Jones, S. Dai, Facilely synthesized meso-macroporous polymer as support of poly(ethyleneimine) for highly efficient and selective capture of $\mathrm{CO}_{2}$, Chemical Engineering Journal 314 (2017) 466476.

[46] E. R. Monazam, L. J. Shadle, D. C. Miller, H. W. Pennline, D. J. Fauth, J. S. Hoffman, M. L. Gray, Equilibrium and kinetics analysis of carbon dioxide capture using immobilized amine on a mesoporous silica, American Institute of Chemical Engineers 59 (2012) 923-935.

[47] Q. Liu, J. Shi, S. Zheng, M. Tao, Y. He, Y. Shi, Kinetics studies of $\mathrm{CO}_{2}$ adsorption/desorption on amine-functionalized multiwalled carbon nanotubes, Industrial \& Engineering Chemistry Research 53 (2014) 11677-11683. 
[48] A. D. Ebner, M. L. Gray, N. G. Chisholm, Q. T. Black, D. D. Mumford, M. A. Nicholson, J. A. Ritter, Suitability of a solid amine sorbent for $\mathrm{CO}_{2}$ capture by pressure swing adsorption, Industrial \& Engineering Chemistry Research 50 (2011) 5634-5641.

[49] M. Songolzadeh, M. Soleimani, M. Takht Ravanchi, Using modified Avrami kinetic and two component isotherm equation for modeling of $\mathrm{CO}_{2} / \mathrm{N}_{2}$ adsorption over a 13X zeolite bed, Journal of Natural Gas Science and Engineering 27 (2015) 831-841. doi:10.1016/j.jngse.2015.09.029.

[50] B. Ohs, M. Krödel, M. Wessling, Adsorption of carbon dioxide on solid aminefunctionalized sorbents: A dual kinetic model, Separation and Purification Technology 204 (2018) 13-20. doi:10.1016/j.seppur.2018.04.009.

[51] M. Avrami, Kinetics of phase change. II Transformation-time relations for random distribution of nuclei, The Journal of Chemical Physics 8 (1940) 212-224. doi:10.1063/1.1750631.

[52] E. R. Monazam, L. J. Shadle, D. C. Miller, H. W. Pennline, D. J. Fauth, J. S. Hoffman, M. L. Gray, Equilibrium and kinetics analysis of carbon dioxide capture using immobilized amine on a mesoporous silica, AIChE Journal 59 (2013) 923-935. doi:10.1002/aic.13870.

[53] H. Freundlich, Über die Adsorption in Lösungen, Zeitschrift für Physikalische Chemie 57U (1907). doi:10.1515/zpch-1907-5723.

[54] Y. S. Ho, J. F. Porter, G. McKay, Equilibrium isotherm studies for the sorption of 
divalent metal ions onto peat: Copper, nickel and lead single component systems, Water, Air, and Soil Pollution 141 (2002) 1-33. doi:10.1023/A:1021304828010.

[55] R. T. Yang, Adsorbents: Fundamentals and Applications, John Wiley \& Sons, Inc., Hoboken, NJ, USA, 2003. doi:10.1002/047144409X.

[56] R. Serna-Guerrero, E. Da'na, A. Sayari, New insights into the interactions of $\mathrm{CO}_{2}$ with amine-functionalized silica, Industrial and Engineering Chemistry Research 47 (2008) 9406-9412. doi:10.1021/ie801186g.

[57] https://www.esrl.noaa.gov/gmd/ccgg/trends/global.html, ESRL Global Monitoring Division - Global Greenhouse Gas Reference Network, accessed on April 4, 2018.

[58] A. Kumar, D. G. Madden, M. Lusi, K. J. Chen, E. A. Daniels, T. Curtin, J. J. Perry, M. J. Zaworotko, Direct Air Capture of $\mathrm{CO}_{2}$ by Physisorbent Materials, Angewandte Chemie - International Edition 54 (2015) 14372-14377. doi:10.1002/anie.201506952.

[59] V. R. Choudhary, S. Mayadevi, A. P. Singh, Sorption isotherms of methane, ethane, ethene and carbon dioxide on $\mathrm{NaX}, \mathrm{NaY}$ and Na-mordenite zeolites, Journal of the Chemical Society, Faraday Transactions 91 (1995) 2935. doi:10.1039/ft9959102935.

[60] I. Langmuir, The constitution and fundamental properties of solids and liquids. Part I. Solids, Journal of the American Chemical Society 38 (1916) 2221-2295. doi:10.1021/ja02268a002.

[61] M. Özacar, I. A. Åđengil, Adsorption of reactive dyes on calcined alunite from aqueous solutions, Journal of Hazardous Materials 98 (2003) 211-224. doi:10.1016/S0304$3894(02) 00358-8$. 
[62] G. Maurin, P. L. Llewellyn, R. G. Bell, Thermodynamics and regeneration studies of $\mathrm{CO}_{2}$ adsorption on multiwalled carbon nanotubes, Journal of Physical Chemistry B 109 (2005) 1608-1609.

[63] S.-C. Hsu, C. Lu, F. Su, W. Zeng, W. Chen, Thermodynamics and regeneration studies of $\mathrm{CO}_{2}$ adsorption on multiwalled carbon nanotubes, Chemical Engineering Science 65 (2009) 1354-1361.

[64] K. J. Laidler, The development of the Arrhenius equation, Journal of Chemical Education 61 (1984) 494.

[65] C. A. Grande, R. P. L. Ribeiro, E. L. G. Oliveira, A. E. Rodrigues, Electric swing adsorption as emerging $\mathrm{CO}_{2}$ capture technique, Energy Procedia 11 (2009) 1219-1225.

[66] R. Ribeiro, C. Grande, A. Rodrigues, Activated carbon honeycomb monolith - zeolite 13x hybrid system to capture $\mathrm{CO}_{2}$ from flue gases employing electric swing adsorption, Chemical Engineering Science 104 (2013) 304-318.

[67] S. Lillia, D. Bonalumi, C. Grande, G. Manzolini, A comprehensive modeling of the hybrid temperature electric swing adsorption process for $\mathrm{CO}_{2}$ capture, International Journal of Greenhouse Gas Control 74 (2018) 155-173. doi:10.1016/j.ijggc.2018.04.012. 